\title{
Taking the biscuit
}

\author{
Tony Delamothe deputy editor
}

The BMJ

Connoisseurs of the perverse will need to look elsewhere for their kicks: England's Cancer Drugs Fund ceases to exist in its current form from next month. The realisation of an election promise made in 2010, the fund has racked up costs of $£ 1.27 \mathrm{bn}$ ( $€ 1.64 \mathrm{bn} ; \$ 1.8 \mathrm{bn}$ ) in its possibly useless life. No data exist to show whether this sum has been spent wisely, both the House of Commons Public Accounts Committee and the National Audit Office concluded.

Nick Timmins identifies the fund as "the biggest single thing that has undermined the role of NICE" in its 17 year history (doi:10.1136/bmj.i1324). Otherwise, he believes that NICE has done a pretty good job of deciding which treatments the NHS should provide. And, as he points out, other countries are very interested in its success.

John Appleby discusses the problem NICE faced from the outset (doi:10.1136/bmj.i1336): "At what point were the benefits generated by an intervention to be deemed worth the cost to obtain them?" Apparently NICE arrived at a threshold range of $£ 20000-£ 30000$ by a "somewhat shady" process in its early days. This threshold is much less generous than WHO's suggested cost effectiveness range and less than half of what it would be now if it had been corrected for inflation and productivity.

NICE hits the headlines when it says no to recommending a drug. Online, however, you can locate just about any prescription drug you want, with its banned, counterfeit, and otherwise dodgy cousins also jostling for attention. Writing about the never ending game of cat and mouse between authorities, buyers, and sellers, Andrew Jack quotes (doi:10.1136/bmj.i1317) the Royal Pharmaceutical Society, which found "everything from crystal meth to brick dust in [online] medicines." More profitable than narcotics, fake pharmaceutical drugs are often made by the same criminal gangs that sell illegal drugs like heroin.

Is sucrose as addictive as heroin? Is obesity best understood as an illness of addiction? Obese people certainly suffer the moral judgment usually reserved for those who can't control their appetites. Something must explain the UK's low uptake of bariatric surgery (doi:10.1136/bmj.i945) despite it being "the most effective treatment for sustained weight loss in people with complex obesity." The overall mortality of the surgery is $0.07 \%$, and the benefits include two thirds of patients with type 2 diabetes being in remission two years after surgery, the possibility of reducing or stopping antihypertensive drugs, and reductions in cholesterol and triglyceride concentrations.

Patients are usually home after one or two days, so general practitioners need to be alert to complications, say Michael Moore and colleagues (doi:10.1136/bmj.i945). They detail the primary care management of patients after weight loss surgery and include an infographic on assessing and referring complications. 